\title{
Städningens politik
}

\section{Vandrerskan}

En bit in i arbetet med denna bok besöker jag en retrospektiv utställning av konstnären Gittan Jönsson. ${ }^{23}$ Utställningslokalens vita salar är, visar det sig, fulla av städande kvinnor. Där är kvinnor som kastar disk, skurkärringar som städar undan atomavfall och en hel liten armé av beslutsamma kvinnliga porslinsfiguriner med dammsugaren i högsta hugg. Framför allt är där en stor, imponerande målning av en kvinna med en vit sjalett om håret, som står högst upp på en bergstopp och blickar ut över ett storslaget, dimhöljt landskap. „Vandrerskan/hommage till Friedrich» heter verket och istället för en vandringsstav (som 18oo-talets sublimt andliga sökare i Caspar David Friedrichs målning »Vandraren över dimhavet« från 1818 stödjer sig på) håller kvinnan en dammsugare i sina händer.

Jönssons målning fångar mycket av det jag velat förmedla $\mathrm{i}$ denna bok. Vandrerskan kan betraktas som en kommentar till den manligt kodade vandraren på väg ut för att upptäcka och erövra världen. Att placera en kvinna med en dammsugare i samma position som äventyraren i Friedrichs målning ger en överraskningseffekt nästintill det skrattretande. Städerskan hör helt uppenbart inte hemma där på berget, inte i vår nutida blick, inte i dåtidens. Snarare hör hon hemma just hemma, på knä under köksbordet eller på en pall med dammsugarslangen i näven i jakt på dammet ovanpå vitrinskåpet. På så sätt blir 
hon en melankolisk påminnelse om att vissa sysslor vetter utåt, bortåt och inte minst framåt, medan andra rör sig i cirklar nedåt och bakåt, mot skräpet och avfallet - och att det som återstår för kvinnan när mannen erövrat världen är att lägga under sig städningen.

Men hon påminner också om att det är möjligt att vända på perspektivet och se det omöjliga som just möjligt. Med en sådan blick blir dammsugerskan en potentiell erövrerska och den kanske minst heroiska av de kvinnligt kodade sysslorna, städning, framstår som en intervention i världen, snarare än en isolering i det privata hemmet. Kanske är vandrerskan att betrakta som en global dammsugerska: det är mycket i världen som behöver städas upp. I 1970-talets kvinnorörelsesammanhang blir hon världssamvetet, med sina »kvinnliga värden som ska rädda världen".

På sätt och vis hade Vandrerskan varit ett perfekt omslag till en bok som undersöker och kritiskt granskar städningens låga status i samhället. Samtidigt är det något som skaver, något som riskerar att gå förlorat i det smått storslagna tilltalet. Städning som praktik är visserligen, som jag visat genom boken, både existentiellt laddad och kulturellt symboltyngd. Den tar tag i vårt innersta och kastar oss bakåt i tiden. Samtidigt kännetecknas den framför allt av motsatsen: nämligen det vardagligt enformiga, utan synbar klimax, det lågmälda snarare än storslagna. Och, som vi alla vet, är risken överhängande att det lågmälda och vardagliga får stå tillbaka för det som gör mer väsen av sig. Därför bestämde jag mig för ett mindre bombastiskt omslag-fortfarande signerat städkonstens okrönta drottning Gittan Jönsson - där dammsugningen snarare än erövring formuleras som något ständigt pågående. Här finns inget berg att bestiga, ingen utsikt att blicka ut över, inte ens en tydlig 
individ att fästa blicken vid. Istället finns här en rad anonyma figurer i kvinnomundering, som städar sig bakåt och nedåt i bilden. Kanske som en påminnelse om att det existentiella och storslagna så att säga finns inrymt i det oglamorösa vardagliga harvandet. I denna bild, tänker jag mig, finns också viktiga politiska poänger att hämta. Jag ska nu, i detta avslutande kapitel, försöka klargöra dessa.

\section{Omsorgsarbetets skuggsida}

Den feministiska rörelsen har, som jag tidigare beskrivit, en synnerligen ambivalent relation till hemmet och hemarbetet. Feminismens »stora berättelse« har huvudsakligen handlat om att ifrågasätta kvinnans naturliga plats i hemmet och bryta sig ur den privata sfären (Felski 2000, Giles 2004). Hemarbetet har i dessa sammanhang kommit att framställas som ett otacksamt slitgöra. Samtidigt har feminister velat synliggöra - och i vissa sammanhang uppvärdera - det osynliga och obetalda omsorgsarbete som är lönearbetets (och livets) förutsättning.

På senare år, menar forskare, ser vi ett förnyat intresse för hemmet och hemmafrutillvaron (Gillis och Hollows 2009, Marander-Eklund 2014). Inte minst massmedia svämmar över av tv-shower och realityprogram där hemmaliv och hemarbete står i fokus. Den matlagande Nigella Lawson framställs i egna tv-shower som en »domestic goddess» och bloggare som Underbara Clara, som delar med sig av husmorstips om alltifrån gardinuppsättningar till bordsdekorationer, får ett eget radioprogram med titeln Husmorsskolan. ${ }^{24}$

Som jag tidigare beskrivit skulle detta nymornade fokus på hemmaliv och hemarbete kunna analyseras som en allmän intimiseringstrend i en värld av kulturell friställning. Kakbak 
och gardinuppsättningar blir, i detta perspektiv, ett utslag för en postfeministisk förhoppning att fă lämna de stora politiska frågorna därhän (Gillis och Hollows 2009). Romantiseringen av hemmafrun blir således att betrakta som en nostalgisk längtan efter en tid som aldrig varit. Men hemmatillvarons "återkomst" kan också tolkas som en rimlig konsekvens av kvinnors dubbelarbete. Inte minst kan den ses som ett erkännande av den paradox som kvinnor tvingas leva i, vad Stéphanie Genz formulerar som "the unresolved struggles between workplace and home" (2009, s. 57). I detta perspektiv blir det möjligt att tolka drömmen om hemmet som varken realiserbar eller ens åtråvärd, utan snarare som just en fantasi för att hantera en svårbemästrad livssituation (Gillis och Hollows 2009).

Hur ser då denna postfeministiska fantasi ut? Ja, inte tycks den innehålla särskilt mycket städning. De underhållningsprogram, reality-shower, bloggar, böcker och tidningsmagasin som uppehåller sig vid hemarbete fokuserar huvudsakligen på barnuppfostran, inredning, matlagning och renovering. En viss upptagenhet av städning som syssla och expertis kan skönjas i exempelvis storsäljare som Marie Kondos (2015) Konsten att städa, där utrensning och organisering av överflödiga prylar står i fokus, eller Marléne Erikssons (2016) Städglädje, som lär ut städning på miljömedvetet vis. Framför allt tycks emellertid medialiseringen av städning, såsom den exempelvis tar sig uttryck i tv-program som TV3:s Rent hus eller brittiska reality-programmet How Clean is Your House, erbjuda tittaren möjligheten att frossa i andra människors röriga liv, snarare än i konsten att städa (Hunt 2009).

Går vi till forskningen ser vi hur den ökade intimisering och hemcentrering som kännetecknar västvärlden visserligen innebär ökade känslomässiga investeringar i hemlivet, något som 
Helene Aarseths (2011) studie visar. Samtidigt verkar framför allt vissa typer av hemarbete kvalificera sig som självutvecklande och därför meningsfulla. Städning, som sorteras in under det Ellinor Platzer (2007) kallar rutinarbete, skapar mindre engagemang och är därför också möjligt att leja ut till andra att göra - för den som har råd. Så ser vi hur städningen helt enkelt inte tycks platsa i kategorin "uppbyggligt» hemarbete.

Intressant nog verkar denna tendens även gälla många feministiska forskare som försökt dröja vid, resonera kring och uppvärdera kvinnors obetalda arbete i hemmet. I en filosofisk tradition återfinns exempelvis tongivande verk som Carol Gilligans In a Different Voice (1982), Nel Noddings Caring. A Feminine Approach to Ethics and Moral Education (1984) och Sara Ruddicks Maternal Thinking: Towards a Politics of Peace (1989), där fokus huvudsakligen ligger på omsorg som erfarenhet och potentiell etik (se även Holm 1993). Och när en feministisk ikon som Iris Marion Young (2000) återvänder till hemmet som symbol, för att synliggöra och lyfta det hon kallar de bevarande aspekterna av tillvaron snarare än byggandet, är det trots allt de till synes mer uppbyggliga delarna hon tar fasta på, medan »mekaniska» sysslor som städning avfärdas som mindre viktiga för hennes teoretiska resonemang.

Min studie, där städningens existentiella dimensioner blivit tydliga, visar emellertid att städning måste betraktas som just en sorts omsorgsarbete. Däremot skiljer det sig på vissa punkter från annan omsorg i hemmet. Den är, i likhet med matlagning, heminredning och barnomsorg, bunden till en specifik plats, nämligen hemmet. Den är, liksom de andra sysslorna, synnerligen genuskodad. Däremot förhåller den sig till tid på delvis andra sätt. Därför vill jag nu slutligen borra än djupare i städningens temporalitet. Jag tänker mig nämligen att de olika 
analyser av temporalitet jag gjort boken igenom kan bidra till en förståelse för städningens roll som en sorts omsorgsarbetets skuggsida - den till synes minst attraktiva av de reproduktiva sysslorna.

Städningens temporalitet

Vad är då möjligt att säga om städning i relation till tid? Först och främst kan vi konstatera att städning, till skillnad från många andra sysslor i hemmet, inte skapar något nytt. Städningen producerar ingenting: den genererar inga nya gardiner, välsmakande kanelbullar eller nyfödda bebisar. Snarare uppfattas den som allra bäst utförd när den varken syns eller märks - och handlar därför huvudsakligen om att söka upprätthålla status quo. Om det obetalda hemarbetet har bestämts som reproduktivt snarare än produktivt, tycks städningen vara den kanske minst produktiva av dessa sysslor. Och om hemarbetet kan karakteriseras av att vara obeständigt - och därför behöva göras om och om igen - tycks städningen fungera som sinnebilden för denna ändlösa repetition.

Vad är då egentligen problemet med repetition? Varför framstår och framställs så ofta repetitivt arbetet som tröstlöst och meningslöst? Lefebvre (1984) menar att vardagslivets repetitiva karaktär uppfattas som ett problem för att det helt enkelt framstår som motsatsen till det moderna samhällets inriktning på framsteg och ackumulation, det vill säga »utveckling». Att regelbundet utföra en syssla innebär att den blir en vana snarare än en överraskning. Detta implicerar en instrumentalisering av tillvaron, där problematisering, intellektualisering och kritiskt tänkande - dygder i det moderna samhället - får stå tillbaka. Vi utför ofta våra rutinartade sysslor per automatik: diskbänken 
torkas medan vi lyssnar på radio och smutskläderna under sängen sorteras undan utan större intellektuell ansträngning. Genom att vara statiskt och förutsägbart snarare än rörligt och dynamiskt fungerar vardagslivet således som en, med Felskis formulering, "retardation device, slowing down the dynamic of historical change«. (2000, s. 81) När Simone de Beauvoir i Det andra könet försöker beskriva hemarbetets förbannelse sker det också i linje med denna förståelse av temporalitet. Hon beskriver en elev, en sextonårig flicka, som ser sin framtid som »ett oändligt uppstigande mot man vet inte vilken topp. Plötsligt, en eftermiddag när modern diskar i köket, förstår hon att moderns händer har dykt ner i det feta vattnet och torkat porslinet med den sträva trasan varje eftermiddag vid samma tid i åratal. Och ända tills hon dör ska dessa händer underkastas samma ritual. Äta, sova, städa ... Åren klättrar inte längre upp mot himlen, de breder ut sig identiska och grå som på en platt bordduk.॥ (2002, S. 525f.)

Städningen (liksom mycket annat hushållsarbete) skulle alltså, enligt detta perspektiv, ha en annan rytm - eller en annan temporalitet - än den historiska framåtriktade tiden. Den är rutinartad, monoton, upprepande och icke-produktiv och uppfattas därför som mindre utvecklande och meningsfull. Personen som utför sysslan blir således också att betrakta som mindre framåtriktad, självständig och fri.

Det finns emellertid fler temporala aspekter av städning som jag tänker mig kan förklara dess låga status - aspekter som delvis skiljer den från annat reproduktivt arbete i hemmet. Som jag diskuterade i kapitel fem är en nyckel till att förstå städningens karaktär att fokusera på det som ska städas undan, själva smutsen. Iris Marion Young (2000) beskriver hemarbetet som en bevarandets praktik - en syssla som skiljer sig från byggandet 
genom att den inte skapar något nytt. Bevarandet kan däremot, påpekar hon, innebära att ge gamla objekt nya meningar, liksom att skapa kontinuitet både framåt och bakåt i tiden. På så sätt kan sysslan upplevas som självutvecklande och meningsfull.

Städning är, som jag visat i tidigare kapitel, just att betrakta som en form av bevarande - ett organiserande och omhändertagande av ting. Samtidigt vill jag, i detta sammanhang, påminna om att städning till stora delar handlar om att röra sig $\mathrm{i}$ närheten av smutsen och skräpet: de avlagringar av liv som huvudsakligen påminner om tillvarons förgänglighet. Att städa innebär att, mot bättre vetande, försöka hålla förfallet stången. Blicken är, så att säga, riktad bakåt och nedåt, snarare än framåt och uppåt. Det är alltså visserligen bevarande vi talar om, men ett bevarande med en annan rörelseriktning. Det är också ett bevarande som, just genom sin riktning, tenderar att upplevas som än mer nödvändigt och oundvikligt än andra former av sorterande. Smutsen lever, som jag visade i förra kapitlet, sitt eget liv, alldeles oavsett hur vi väljer att leva våra liv. Vare sig vi har familj och barn eller ej, bor i slott eller koja, är det pågående förfallet ett tillstånd vi alla delar. Att städa blir därför en påminnelse om att vi är underkastade tidens gång - att tillvaron helt enkelt är villkorad av smutsen och det eviga runttrampandet på stället.

Istället för att betona städningens bevarande aspekter i termer av nytolkande och uppbygglighet vill jag därför lyfta fram just det som uppfattas som motsatsen, det arbete som snarast kan förstås som ett ständigt pågående, nödvändigt hanterande av förgänglighet. Det är nämligen här jag tror mig finna en möjlig förklaring till städningens låga status - och också här jag tänker mig att den blir som mest politiskt brännbar. 


\section{En utopi?}

Som jag beskrev i inledningskapitlet är många feministiska forskare kritiska till en genuskodad uppdelning i cirkulär och linjär tid, en sorts stiliserad hantid och hontid (Felski 200o). Det är exempelvis möjligt att fråga sig huruvida (det historiskt sett manligt kodade) lönearbetet, med sina åtta arbetstimmar fem dagar i veckan, är mindre repetitivt än exempelvis veckostädningen. Dessutom är det, som flera av intervjupersonerna beskriver, tveksamt om repetition med nödvändighet behöver upplevas som meningslöst och outvecklande. Framför allt, som Felski påpekar, existerar de olika formerna av tid sida vid sida och går in i och ut ur varandra.

Poängen här är snarare att vi, i ett samhälle som bygger på en linjär tidsuppfattning där uppdelningen mellan produktivt och reproduktivt arbete är central, har lärt oss att betrakta det ena som tröstlöst och det andra som både lönsamt och självutvecklande. Detta betyder i sin tur att vissa sysslor - och de människor som åläggs att utföra sysslorna - får lägre status, lägre ekonomisk ersättning och föga kulturellt erkännande. Efter att i denna bok ha djupdykt i städningen, både som den upplevs i praktiken och tolkas symboliskt, blir frågan jag ställer mig: går det att vända på saken? Är det möjligt att omfamna städningens temporalitet snarare än att sky den - att urskilja en potentiell politisk poäng i den repetitiva, till synes improduktiva rörelsen bakåt och nedåt?

I sin smått dystopiska No Future pläderar Lee Edelman (2004) för det han kallar den antisociala vändningen i queerteori. Hans poäng är att den enda möjligheten att politiskt motsätta sig krononormativiteten, det vill säga den kapitalistiska "tvångstanken« om tiden som ett ständigt framåtskridande med ökad produktivitet, är att omfamna negativiteten och avsäga sig 
investeringar i framtiden. Att helt enkelt göra sig omöjlig att exploatera i framtidens tjänst.

Edelmans tankar är relevanta i detta sammanhang, kanske framför allt för att de synliggör det potentiella motstånd som andra tidsrytmer utgör i vårt samhälle. I en tid genomsyrad av uppmaningar att söka sig vidare, bryta upp, blicka framåt och lägga bakom oss, framstår städandets till synes grådassiga temporalitet som i det närmaste en förolämpning. Vi blir helt enkelt arga, uppgivna och irriterade av tanken på att behöva plocka fram dammsugaren ännu en gång - när den nyss var framme. Städningens repetitiva rytm, det till synes tröstlösa trampandet på stället, bjuder därför motstånd mot dominerande föreställningar om vad som räknas som riktigt och viktigt i samhället.

Vad mer är: städningens riktning bakåt och nedåt, mot förfallet och förgängligheten snarare än mot det till synes uppbyggliga, utgör i sig ett potentiellt grus i maskineriet. Det är åtminstone så jag tolkar den relativa avsaknaden av kommersiell exploatering av städning, i en kultur som annars gör pengar på det som är möjligt. Som jag tidigare beskrivit är den uppsjö av produkter, tidningar, tv-program och böcker som uppehåller sig vid hemmet och sysslorna i hemmet sällan inriktade på städning. Städningen går visserligen att leja ut och göra sig av med, i form av lågt betalt arbete. Däremot tycks den långt svårare att göra till hobby eller livsstil. På så sätt skulle dammet kunna liknas vid den queera positionen i Edelmans tankefigur - något som svårligen låter sig »domesticeras».

Med dessa resonemang i bakhuvudet vill jag nu återvända till städningens betydelse som omsorg och omhändertagande - och återigen skriva in städandet i en tradition av kvinnligt kodat omsorgsarbete. För medan Edelmans svartsynta utopi 
bygger på det antisociala och introspektiva, är städningen trots allt relationell. Ytterst sett handlar den om att ta omhand - kanske inte främst framtida liv utan snarare det pågående nuet och ständiga förfallet: tillvarons rester. Simone de Beauvoirs beskrivning av husmoderns tröstlösa trampande på stället med formuleringen: "hon gör ingenting, hon förevigar bara nuet" $(2002,525)$ tjänar, tänker jag mig, alltså mindre som beskrivning av Edelmans omfamnande av den asociala negativiteten, än av en sorts omhändertagande av nuet. En omsorg i gråtoner, som genom sitt upprepande och fokus på förfallet inte väjer för det döda eller döende.

En sådan omsorg, tänker jag mig, pekar också mot ett annat möjligt meningsskapande än det framåtblickande individuella självförverkligandet. Det medlevande med tingen som städningen utgör skapar, som jag visat, både förankring och mening. Att, som Johanna uttrycker det, "pilla med sina saker", innebär att skriva in sig i en rörelse av städande kroppar över tid - och på så sätt överskrida sig själv och sin individualitet. Genom att kapitulera inför det livets grundvillkor som förfallet och tidens gång utgör, synliggörs hur beroende och omhändertagande måste betraktas som livets förutsättning snarare än en black om foten.

Mot bakgrund av detta resonemang vill jag retirera till den praktiska vardagsstädningen. Poängen med min undersökning är ju, trots allt, att låta det konkreta, praktiska städandet stå i förgrunden för de (till synes oemotståndliga) abstraktionerna om renhet och smuts. Att helt enkelt hålla mig närmre dammet. En sådan påminnelse utfärdar också Gillis och Hollows (2009) när de konstaterar vikten av att skapa möjligheter att undersöka domesticitet och hemarbete som varken hamnar i föreställningar om förtryck och tristess eller romantisering av 
»kvinnliga värden«. Genom att entydigt upp- eller nedvärdera riskerar vi nämligen att missa själva poängen - de lärdomar vi eventuellt kan dra ur det vardagligas vardaglighet. Frågan återstår nämligen: hur skulle en politik kunna se ut som tar städningens praktik i beaktan?

Städningens politik

I boken Lyckliga i alla sina dagar hävdar Nina Björk (2012) att den feminism som har segrat i Sverige (liksom i övriga västvärlden) inte är den utopiska utan den rättighetsliberala. Det denna feminism är bäst på, skriver Björk, är att försvara kvinnors rätt att vara som män traditionellt har varit: att arbeta som dem, att få samma rättigheter, makt och lön som dem och, inte minst, samma möjligheter att lämna hemmet. Samtidigt kvarstår en rad problem som har med hemmet, hemarbetet och "det lilla livet" att göra. För trots en delvis feministiskt frammanad politik med offentligt finansierad omsorg, heltidsanställningar och möjlighet för vissa mer bemedlade att köpa hushållstjänster står vi fortfarande med samma olösta problem - alla dessa mänskliga behov. Frågan vi måste ställa oss är: vad gör vi med de, med Nancy Frasers (2003, s. 114) formulering, förrymda behoven i ett samhälle där bara visst arbete räknas? Vad gör vi, som feminister, med alla toaletter som ska skuras, små näsor som behöver snytas, mormödrar vars gräsmattor behöver klippas och vintervantar som måste letas fram ur förrådet?

I Feminism som lönearbete pläderar Maria Carbin, Elin Kvist och Johanna Overud (2017) för en feministisk lönearbetskritik som politisk vision. I linje med exempelvis Kathi Weeks (2011) vill de koppla samman vänsterns arbetskritik, där lönearbete huvudsakligen ställs mot en möjlig fritid, med frågan om det 
reproduktiva arbetet i hemmet. I en sådan samhällsmodell skulle lönen vi tjänar inte baseras på vår delaktighet i produktionen av värde, utan i reproduktionen av liv. Snarare än produktivitet, självständighet, frihet och individualitet skulle det ömsesidiga beroendet och sårbarheten sättas i fokus. Detta innebär att människors beroende inte nödvändigtvis betraktas som något som ska övervinnas eller kompenseras. Snarare är det ett mänskligt villkor vi alla delar. Nancy Fraser (2013) formulerar alternativet som en »universell omsorgsgivarmodell», som utgår från att vi alla - genom att vi lever tillsammans - både är sårbara och behövande och samtidigt omsorgsgivare.

En feministisk lönearbetskritisk omsorgsetik, som det ju är frågan om här, måste helt enkelt vila i och omfamna sårbarheten både som villkor och norm (jfr Tronto 2013). Jag tänker mig också att den här sortens politik måste vara alldeles särskilt vaksam på det temporala.

Istället för att utgå från de till synes uppbyggliga, produktiva och framåtblickande aspekterna av omsorgsarbetet föreslår jag städandet, med sin rörelse bakåt och nedåt, som en rimlig utgångspunkt för en sådan vision. Hur ett samhälle städar, hur vi tar hand om resterna, skräpet och det som blir över, torde vara en utmärkt utgångspunkt för hur väl vi ombesörjer våra gemensamma behov.

Kanske är tiden inne, tänker jag, när jag i vinterslasket sträckläser Kristina Sandbergs 1500 sidor långa hyllning till hemmafrun Maj. Alldeles uppenbart är det åtminstone möjligt att under tvåtusentalets andra decennium göra en feministisk omläsning och uppvärdering av ett arbete som huvudsakligen har fungerat som feminismens »andra». Om hemmafrun och hemarbetet hittills har haft ett påfallande motsägelsefullt eftermäle, pendlande-som Annelie Bränström-Öhman (2016, s. 
17) skriver - »mellan skam, förnekelse och nostalgi», tycks saker och ting vara i förändring. Detta syns inte minst i det översvallande mottagandet av romantrilogin, alldeles särskilt av feministiska forskare och skribenter (se t.ex. Williams 2014, Jönsson 2016, Arping 2017).

Sandberg skriver sin roman från positionen som dotterdotter, ett distanserande perspektiv som kanske är nödvändigt för att projektet alls ska vara möjligt. Att sida efter sida låta den "obetydliga» hemmafrun få bre ut sig om kaffebrickor, bajsblöjor och klibbigt damm framstår, med tiden i ryggen, som ett synnerligen solidariskt projekt. Med det eviga skurandet och fejandet i förgrunden tvinnas så, med Jörngårdens formulering (2017, s. 122), feministen och hemmafrun samman i ett empatiskt och solidariskt förbund. Ett förbund som, förhoppningsvis och av nödvändighet, inte stannar vid nostalgiskt tillbakablickande, utan även inkluderar de lågbetalda, ofta rasifierade, kvinnor som under osäkra villkor städar andras hem. Ett förbund som helt enkelt förmår rikta blicken mot vardagsstädningens praktik och politik, där och då liksom här och nu.

Med dessa ord vill jag återvända till Tove Janssons Filifjonka, hon jag inspirerats av för att få syn på den »diskbänksexistentialism« jag tycker att städningens praktik och politik besitter. ${ }^{25}$ Filifjonkan pendlar mellan förtvivlan, raseri och eufori i sin städningsneuros. Men ibland är hon också alldeles tillfreds med städningen som syssla. Det repetitiva, igenkännbara och ständigt återkommande arbete som smälter ihop då, nu och framtid i en evigt gungande vågrörelse:

"Det var en gång en Filifjonka som tvättade sin stora trasmatta i havet. Hon gnodde med tvål och borste ända fram till den 
blåa randen och så väntade hon på var sjunde våg som kom precis lagom för att skölja bort tvålskummet.

Sen tvättade hon till nästa blåa rand och solen värmde hennes rygg och hon stack ner sina smala ben i det genomskinliga vattnet och gnodde och gnodde.» (Jansson 1998, s. 37) 